\title{
Long-term storage of mouse spermatozoa after evaporative drying
}

\author{
Ming W Li, John D Biggers ${ }^{1,2}$, Heidi Y Elmoazzen², Mehmet Toner², Lynda McGinnis ${ }^{1,2}$ \\ and K C Kent Lloyd \\ School of Veterinary Medicine, Center for Comparative Medicine, University of California, Davis, California 95616, \\ USA, ${ }^{1}$ Department of Cell Biology, Harvard Medical School, Boston, Massachusetts 02115, USA and ${ }^{2}$ Center for \\ Engineering in Medicine, Massachusetts General Hospital, Harvard Medical School and Shriners Hospital for \\ Children, Boston, Massachusetts 02115, USA
}

Correspondence should be addressed to K C K Lloyd; Email: kclloyd@ucdavis.edu

L McGinnis is now at Department of Molecular and Integrative Physiology, University of Kansas Medical School, Kansas City, Kansas, USA

\begin{abstract}
To determine if mouse spermatozoa could be preserved long-term without using liquid nitrogen, mouse spermatozoa in trehalose-EGTA solution were partially evaporatively dried under nitrogen gas $(5 \mathrm{~min}$ at flow rate10 $\mathrm{l} / \mathrm{min}$ ) and stored for 1 week and 5 months at $4,-20$, and $-80^{\circ} \mathrm{C}$ before intracytoplasmic sperm injection. Fertilization rates were neither different with spermatozoa stored at $4,-20$, or $-80^{\circ} \mathrm{C}$ for 1 week or 1,3 , and 5 months respectively, nor blastocyst formation rates with spermatozoa stored for 1 week and 1 month. However, spermatozoa stored at 4 and $-20^{\circ} \mathrm{C}$ for 3 months resulted in fewer blastocysts (35.1 and $54.3 \%$ respectively) when compared with spermatozoa stored at $-80{ }^{\circ} \mathrm{C}(74.4 \%)$. Blastocyst formation rates using spermatozoa stored for 5 months at $-20^{\circ} \mathrm{C}(57.4 \%)$ or $-80^{\circ} \mathrm{C}(74.5 \%)$ were not significantly different from those stored for 3 months at the same temperatures respectively, but were significantly better than those stored for 5 months at $4{ }^{\circ} \mathrm{C}$ $(\mathbf{1 0 . 2} \%)$. Blastocysts derived from spermatozoa stored for 3 and 5 months at -20 and $-80{ }^{\circ} \mathrm{C}$ respectively, were then transferred to pseudopregnant mothers to develop into healthy liveborn offspring. No significant differences were found in embryo transfer rates (number of pups born/number of embryos transferred), weaning rates, or sex ratios of resultant pups, which were healthy and reproductively sound. These results demonstrate for the first time that partially evaporatively dried mouse spermatozoa in trehalose-EGTA solution can be preserved for long term at -20 and $-80^{\circ} \mathrm{C}$. The possibility that the storage temperature must be less than the glass transition temperature is discussed.
\end{abstract}

Reproduction (2007) 133 919-929

\section{Introduction}

The mouse has been, and will continue to be, an important animal model in biological and biomedical research. Across the world, animal use facilities are overflowing with mutant mice as significantly more new mouse lines are generated each year (Sharp et al. 2001, Knight \& Abbott 2002). The conventional way of 'preserving' the induced mutant mouse genotypes are colony breeding and embryo banking. However, it is now widely acknowledged that sperm preservation is a substantially more efficient and cost-effective approach.

The traditional method for mouse sperm preservation is cryopreservation in liquid nitrogen (Nakagata 2000, Landel 2005), but since the advent of mouse intracytoplasmic sperm injection (ICSI) technique
(Kimura \& Yanagimachi 1995), alternative approaches to simplify the methodology of mouse sperm preservation have been explored, including freeze-drying (Wakayama \& Yanagimachi 1998, Kusakable et al. 2001, Ward et al. 2003, Kaneko \& Nakagata 2005, Kawase et al. 2005), evaporative drying (Bhowmick et al. 2003, McGinnis et al. 2005), and storage under hyperosmotic conditions (Van Thuan et al. 2005). Compared with freeze-drying, sperm-evaporative drying has the advantages that it does not require liquid nitrogen and a freeze-dryer machine for sample preparation. It was reported that mouse spermatozoa could be dried under a stream of nitrogen gas at ambient temperature and stored overnight at $4{ }^{\circ} \mathrm{C}$ (Bhowmick et al. 2003) without loosing their ability to fertilize the ova after ICSI and support embryo 
development in vitro to the blastocyst stage and development in vivo to day 15 after embryo transfer into pseudopregnant foster mother. More recently, it was reported that, after storage at $4{ }^{\circ} \mathrm{C}$ for 3 months, some of the evaporatively dried mouse spermatozoa that had been permeabilized with $\alpha$-hemolysin to allow entry of trehalose before evaporative drying were still capable of supporting embryo development in vitro to blastocyst stage and generating liveborn offspring after ICSI (McGinnis et al. 2005).

For evaporative drying to be of practical use, it must be able to preserve the spermatozoa to ensure viability after long-term storage. An earlier study showed that evaporatively dried mouse spermatozoa could be preserved longer at $4{ }^{\circ} \mathrm{C}$ than $22^{\circ} \mathrm{C}$, although sperm deterioration also occurred as soon as 4 weeks of storage at $4{ }^{\circ} \mathrm{C}$ had elapsed (McGinnis et al. 2005). A similar phenomenon was found in freeze-dried mouse spermatozoa (Kaneko \& Nakagata 2005, Kawase et al. 2005) and heat-dried bull spermatozoa (Lee \& Niwa 2006). The purpose of the present study was to find storage conditions for evaporatively dried mouse spermatozoa that prevent rapid deterioration. Our results demonstrate that evaporatively dried mouse spermatozoa can be stored at $-80{ }^{\circ} \mathrm{C}$ without serious deterioration for up to 5 months.

\section{Materials and Methods}

\section{Reagents and media}

$\mathrm{KSOM}^{\mathrm{AA}}$ medium (Biggers et al. 2000) and FHM medium (Hepes-buffered KSOM medium; Lawitts \& Biggers 1993) were purchased from Specialty Media (Phillipsburg, NJ, USA). Polyvinyl pyrrolidone (PVP) was purchased from Irvine Scientific (Santa Ana, CA, USA), mercury from Fisher Scientific, and trehalose dehydrate from Ferro-Pfanstiehl Laboratories, Inc. (Waukegan, IL, USA). All other chemicals were obtained from Sigma Chemical Co. Na-K-EGTA medium used to collect spermatozoa was Tris-buffered EGTA solution containing

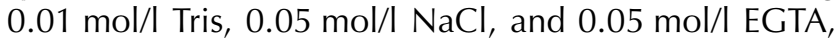
$\mathrm{pH}$ adjusted to 8.2 using $\mathrm{KOH}$ solution. Na-K-EGTA medium supplemented with $0.5 \mathrm{~mol} / \mathrm{l}$ trehalose (referred to as trehalose-EGTA), used as the sperm-drying medium, was prepared as a $2 \times$ stock solution and was stored at $4{ }^{\circ} \mathrm{C}$ before use. $\alpha$-Hemolysin from Staphylococcus aureus, used to create transmembrane channels in the sperm plasma membrane through which trehalose was loaded (Eroglu et al. 2000, Acker et al. 2003), was prepared as a $2 \times$ stock solution $(25 \mu \mathrm{g} / \mathrm{ml})$ in Hepesbuffered saline solution containing $0.01 \mathrm{~mol} / \mathrm{l} \mathrm{NaCl}$, $0.12 \mathrm{~mol} / \mathrm{l} \mathrm{KCl}, 0.005 \mathrm{~mol} / \mathrm{l}$ glucose, and $0.02 \mathrm{~mol} / \mathrm{l}$ Hepes (pH 7.4), and was stored at $-20^{\circ} \mathrm{C}$ before use (McGinnis et al. 2005).

\section{Animals}

Six- to twelve-week-old female B6C3F1 (C57BL/6) $\times$ $\mathrm{C} 3 \mathrm{H} / \mathrm{HeJ}$ ) mice and 10- to 16-week-old male B6D2F1 $(\mathrm{C} 57 \mathrm{BL} / 6 \mathrm{~J} \times \mathrm{DBA} / 2 \mathrm{~J})$ mice (The Jackson Laboratory, Bar Harbor, ME, USA) were used as oocyte and sperm donors respectively. All the males had been mated 1-2 weeks before use for sperm collection to ensure that the males used were fertile as determined by pregnancy of the plugged females 2 weeks later. Eight- to ten-week-old CD-1 (Charles River Laboratories, Inc., Wilmington, MA, USA) mice were used to produce vasectomized males and pseudopregnant females for embryo transfer using standard procedures. All mice were maintained in ventilated cages (BioZone Inc., Fort Mill, SC, USA) and fed (LabDiet, Richmond, IN, USA) and watered in individually ventilated caging in rooms maintained on a $14 \mathrm{~h}$ light:10 $\mathrm{h}$ darkness cycle.

\section{Sperm treatment}

Sperm treatment was performed using modifications to a previously published method (McGinnis et al. 2005). Briefly, spermatozoa were harvested from B6D2F1 male mice, killed by $\mathrm{CO}_{2}$ inhalation and cervical dislocation, by gently puncturing and expressing spermatozoa from the caudal epididymides using sterile needles under a dissecting microscope into $0.5 \mathrm{ml}$ prewarmed $\mathrm{Na}-\mathrm{K}-$ EGTA medium. After removal of the epididymal tissue, the spermatozoa were incubated at $37.5^{\circ} \mathrm{C}$ for $10 \mathrm{~min}$ to allow for sperm dispersion. Then, $100 \mu \mathrm{l}$ sperm suspension were mixed with an equal volume of $2 \times$ hemolysin stock solution to permeabilize the spermatozoa for $30 \mathrm{~min}$ at room temperature in the dark. After permeabilization, $200 \mu \mathrm{l}$ of $1.0 \mathrm{~mol} / \mathrm{l}$ trehalose in Na-K-EGTA medium were added (final concentration of trehalose $0.5 \mathrm{~mol} / \mathrm{l})$ to the sperm suspension and mixed, and the sperm suspension was allowed to settle for $15 \mathrm{~min}$ at room temperature in the dark. After trehalose loading, sperm samples were kept on ice before evaporative drying.

\section{Evaporative drying}

Instrumentation and procedures were the same as those described previously (Bhowmick et al. 2003, McGinnis et al. 2005). Briefly, after trehalose loading of spermatozoa as described previously, $20 \mu \mathrm{l}$ sperm suspensions were placed within a $10 \mathrm{~mm}$ circular area demarcated on a sterile glass slide (Ted Pella, Inc., Redding, CA, USA). The slide was then placed into a drying chamber (Bhowmick et al. 2003) and evaporatively dried by blowing compressed ultra pure grade nitrogen gas directly through the chamber for $5 \mathrm{~min}$ at a flow rate of $10 \mathrm{l} / \mathrm{min}$. The residual water (weight of water in evaporatively dried sperm sample/weight of water in sperm sample before evaporative drying) was about $8 \%$ 
(w/w; McGinnis et al. 2005), and previous work has shown that further drying is deleterious to mouse sperm (McGinnis et al. 2005). Afterwards, a silicone isolator ('Press-to-Seal Without Adhesive'; Grace Bio-Labs, Bend, OR, USA) was placed around the partially dried sperm sample and covered with a sterile glass coverslip. The slide was vacuum-sealed (Impak Corporation, Los Angeles, CA, USA) in a 5 in. $\times 2$ in. plastic bag (Food Saver Vac-Loc, Tilia International, Inc., San Francisco, CA, USA) which was then vacuum-packed into a 6 in. $X$ 3 in. Mylar foil bag (Impak). Vacuum-sealed bags were stored at $4,-20$, or $-80{ }^{\circ} \mathrm{C}$, for 1 week and 1,3 , and 5 months, ensuring that slides remained flat with sperm facing up.

\section{Superovulation}

Female B6C3F1 mice were superovulated by injection of $5 \mathrm{IU}$ pregnant mare serum gonadotrophin (i.p.), followed 46-48 h later by injection of $5 \mathrm{IU}$ human chorionic gonadotropin (hCG), i.p. Mice were killed by $\mathrm{CO}_{2}$ inhalation and cervical dislocation 13-14 h after hCG injection. After disinfection and opening of the abdomen, oocyte-cumulus complexes (OCCs) were collected from oviducts into warm FHM medium. Cumulus cells were dissociated from OCCs by treatment with $300 \mathrm{U} / \mathrm{ml}$ bovine testis hyaluronidase in FHM medium for about $5 \mathrm{~min}$ at room temperature. Freed oocytes were collected and washed in equilibrated $\mathrm{KSOM}^{\mathrm{AA}}$ medium in which they were then incubated at $37.5{ }^{\circ} \mathrm{C}$ in humidified $5 \% \mathrm{CO}_{2}$ and $95 \%$ air. Oocytes were used for ICSI within 3-h collection.

\section{ICSI}

Holding and injection pipettes were prepared from borosilicate glass capillaries (Sutter Instrument Co., San Rafael, CA, USA) using a micropipette puller (Model P-97, Sutter Instrument Co.) and a Narishige microforge. The holding pipette had an external diameter of $60-80 \mu \mathrm{m}$ and internal diameter of $10-15 \mu \mathrm{m}$. The injection pipette had an external diameter of 7-8 $\mu \mathrm{m}$ and internal diameter of 6-7 $\mu \mathrm{m}$. The ICSI procedure was performed on a Nikon TE200 inverted microscope with Narishige micromanipulators. Mercury (2-3 mm long) was back loaded and pushed to the tip of the injection pipette by distilled water from a syringe. The cover of a plastic dish (100 $\mathrm{mm} \times 15 \mathrm{~mm}$; Falcon) was used as the microinjection chamber.

Before beginning ICSI, the package containing the sperm sample was cut open, the cover glass and gasket were removed, and the sperm sample was rehydrated by addition of $20 \mu \mathrm{l}$ BSA-free FHM medium containing $0.01 \%(\mathrm{w} / \mathrm{v})$ polyvinyl alcohol (PVA, cold water soluble, MW 30-70 kDa). Sperm samples stored at $4{ }^{\circ} \mathrm{C}$ were rehydrated for $5 \mathrm{~min}$ at room temperature and a little sperm suspension was transferred to the ICSI dish. Frozen samples $\left(-20\right.$ or $\left.-80^{\circ} \mathrm{C}\right)$ were thawed at $37^{\circ} \mathrm{C}$ for $5 \mathrm{~min}$ before opening the sperm package and sperm rehydration.

ICSI was performed using modifications to a previously published procedure (Li et al. 2003, Li \& Lloyd 2006). Briefly, a small amount of rehydrated sperm suspension was transferred using a mouth pipette into a $5 \mu \mathrm{l}$ drop of $10 \%$ PVP (w/v, in BSA-free FHM medium) under mineral oil and mixed thoroughly. An individual spermatozoon was aspirated, tail first, into the injection pipette, and then one to a few piezo pulses were applied to the neck region (intensity 4-5, speed 2-3; PMM controller, Prime Tech, Ibaraki, Japan) to separate the sperm head from the tail. After a group of sperm heads (about ten sperm heads in 2-3 min) was prepared in this fashion, they were aspirated into an injection pipette and then expelled into another 10\% PVP drop to wash away any adherent EGTA and trehalose. The washed sperm heads were loaded into the injection pipette with short intervals of 10\% PVP between sperm heads, and then the loaded injection pipette was moved to a drop of FHM medium (containing $0.01 \%$ PVA to replace BSA) for ICSI.

A group of oocytes (around ten) was transferred into the FHM drop and each individual oocyte was held by suction to the holding pipette at the $9^{\prime}$ o clock position so that the metaphase II spindle was visible at either 12 or $6^{\prime}$ o clock position. The injection pipette was advanced to penetrate the zona pellucida at the $3^{\prime} \mathrm{O}$ clock position after applying several piezo-pulses (intensity $2-4$, speed 3 ). The zona piece was expelled into the perivitelline space and the injection pipette was advanced against the oolemma to the opposite side of the oocyte's cortex. The oolemma was punctured by applying 1 weak piezo pulse (intensity $1-2$, speed 1 ), and a sperm head was released into the ooplasm with minimum medium. Sperm samples exposed to three different storage conditions $\left(4,-20\right.$, and $\left.-80^{\circ} \mathrm{C}\right)$ were injected on each day of ICSI.

\section{Embryo culture and embryo transfer}

Injected oocytes were washed and incubated in equilibrated $\mathrm{KSOM}^{\mathrm{AA}}$ medium $(50 \mu$ drops under mineral oil) at $37.5{ }^{\circ} \mathrm{C}$ in humidified $5 \% \mathrm{CO}_{2}$ and $95 \%$ air for $24-98 \mathrm{~h}$ for different experimental purposes. Embryos were graded for stage of development every $24-h$ post-ICSI. For in vivo experiments, embryos were transferred at 2-cell stage into the oviducts (0.5 days post-coitum recipients) or at blastocyst stage into the uterus (2.5 days post-coitum recipients) of the pseudopregnant CD-1 mice. For oviduct transfer, each group of 2-cell embryos was divided into two approximately equal sub-groups and each transferred into one or other oviduct of a recipient. For uterine transfer, if the number of blastocysts per group was more than 6, each was 
divided into two approximately equal subgroups and each transferred into one or other uterine horns of a recipient; if $<6$ blastocysts, only one uterine horn was used. Recipients were kept warm on a heating pad until fully recovered from anesthesia. Avertin $(2.5 \%$, v/v) was used as an anesthetic.

The offspring (F1 generation) were born 18-21 days after transfer and pups were weaned at 21 days of age. One male and one female mouse from each litter were randomly chosen as a breeding pair (for some litters, two breeding pairs were randomly chosen from each litter) for natural mating to produce the second (F2) generation.

\section{Experimental design and statistical analysis}

The effect of storage temperature $\left(4,-20\right.$, and $\left.-80^{\circ} \mathrm{C}\right)$ was examined in a comparative replicated experiment consisting of three replicates for each storage time. The responses of the preimplantation embryos in vitro were scored as an ordered developmental sequence: numbers of 1-cell embryos that survived ICSI, 2-cell embryos (assumed to estimate fertilization rate), 3,4-cell embryos, uncompacted morulae, compacted morulae, zonaenclosed blastocysts, and hatching blastocysts. The results obtained in each replicate within an experiment were summarized as a single-ordered contingency table and their homogeneity tested with the Kruskal-Wallis significance test, and the probabilities were computed exactly using StatXact 7 software (Cytel Statistical Software, Cambridge, MA, USA). Since the patterns of the distributions of the embryonic stages that developed appeared similar in all the replicates, the data were pooled over replicates, yielding double-ordered $r \times c$ contingency tables relating the embryonic stages reached in vitro to the storage temperatures. The probability that the distributions of the embryonic stages were the same at all storage temperatures was tested using the Jonckhere-Terpstra significance test. Again, the exact probabilities were computed using StatXact 7 . The embryo transfer data were analyzed by expressing the results as single ordered $3 \times 2$ contingency tables and applying the exact Kruskal-Wallis test of significance. Logistical regression analysis was done on the data of each sperm storage temperature using LogXact 7 (Homer \& Lemeshow 1989, McCullagh \& Nelder 1989; Cytel Statistical Software). It is assumed in this analysis that each spermatozoon has a unique survival time, and that the variation in survival times in a population of spermatozoa is modeled by the logistic distribution. The form of the fitted equation was:

$y=\operatorname{logit} p=a+b t$

where $\operatorname{logit} p=\ln (p /(1-p))$, i.e. the natural logarithm of the odds ratio, $p$ is the proportion of responders in each treatment group, $b$ is a regression coefficient, $a$ is a constant, and $t$ is the time of storage. The conventional $P=0.05$ level was used to evaluate significance in all the statistical analyses. Using the Arhennius relation, a plot was constructed by plotting the $\ln (b)$ versus the reciprocal of the absolute storage temperature ( $T$ in $K$ ).

\section{Theoretical estimation of the glass transition temperature}

The glass transition temperature is one of the key parameters to determine storage stability in the dried state. There are several possible methods to measure the glass transition temperature, such as differential scanning calorimetry, Fourier transform infrared spectroscopy, and thermally stimulated depolarization currents. However, to measure the glass transition temperature is experimentally challenging, since the minimum amount of material required to measure the glass transition temperature by any method is about 10-150 mg (Katkov \& Levine 2004). This amount is significantly more than the weight of our dried samples of spermatozoa that were $4-5 \mathrm{mg}$ on the slide. However, it is possible to make theoretical calculations and estimate the glass transition temperature as a function of the constituents of a solution. There are many models that have been suggested to predict the glass transition temperature (Katkov \& Levine 2004). The Gordon-Taylor formalism is one such model that has been used to predict the glass transition temperature of the binary mixture of water and trehalose (Chen et al. 2000). The Gordon-Taylor equation is given as follows:

$T_{\mathrm{g}}=\frac{w_{1} T_{\mathrm{g} 1}+K w_{2} T_{\mathrm{g} 2}}{w_{1}+K w_{2}}$

In this equation, subscript 1 refers to the solute (trehalose) and subscript 2 refers to the solvent (water). $T_{\mathrm{g}}$ is the glass transition temperature, $w$ is the weight fraction, and $K$ is an empirically determined parameter, which has been calculated to have a value of 5.2 (Chen et al. 2000). In order to use the Gordon-Taylor equation to predict the glass transition temperature, the glass transition of pure trehalose, $T_{\mathrm{g} 1}$, and pure water, $T_{\mathrm{g} 2}$, must be specified. The glass transition temperature for pure trehalose has been found to be $100^{\circ} \mathrm{C}$ (Roos 1997), while the glass transition temperature for pure water has been found to be $-135^{\circ} \mathrm{C}$ (Green \& Angell 1998). From previously published work, using similar drying protocols to the one used in this study (McGinnis et al. 2005) as well as unpublished results, the water content after drying relative to the total dry weight of the other components, $q$, of the sample was found to be $\sim 0.26 \mathrm{~g} \mathrm{H}_{2} \mathrm{O} / \mathrm{g}$ dry weight:

$q=\frac{m_{\mathrm{w}}}{m_{\mathrm{d}}}=\frac{m_{\mathrm{s}}-m_{\mathrm{d}}}{m_{\mathrm{d}}}$ 
where $m_{\mathrm{w}}$ and $m_{\mathrm{d}}$ are the mass of water and dry mass respectively and $m_{\mathrm{s}}$ is the total mass of the sample. The water content after drying relative to the total dry weight of the other components is related to the weight fraction of the solute, $w_{2}$ in the following manner (Katkov \& Levine 2004):

$w_{2}=\frac{q}{1+q}$

For a binary solute-water system, the weight fraction of the water, $w_{1}$, is related to the weight fraction of the solute by the following relationship: $w_{1}=1-w_{2}$. For a $q$ value of $0.26 \mathrm{~g} \mathrm{H}_{2} \mathrm{O} / \mathrm{g}$ dry weight, the weight fraction of the solute (trehalose), $w_{1}$, is 0.206 and the weight fraction of the solvent fraction (water), $w_{2}$, is 0.794 . Using the Gordon-Taylor equation, the glass transition temperature for our dried samples was calculated to be $-35^{\circ} \mathrm{C}$. For systems that contain high glass formers such as trehalose, the only way to achieve a stable glass is to cool the dried sample below its glass transition temperature ( $T_{\text {storage }}<T_{\mathrm{g}}<T_{\text {drying; }}$ Crowe et al. 2001, Katkov \& Levine 2004).

\section{Results}

\section{Effects of sperm storage time and temperature on fertilization}

Mouse spermatozoa were evaporatively dried for $5 \mathrm{~min}$ at a flow rate of $10 \mathrm{l} / \mathrm{min}$ and vacuum-sealed before being stored at $4,-20$, and $-80^{\circ} \mathrm{C}$ for 1 week and 1 , 3 , and 5 months before ICSI. There were no significant differences between the numbers of fertilized oocytes injected with evaporatively dried spermatozoa that developed to the 2-cell stage after storage at any of the tested temperatures and storage times (Table 1). Overall, the fertilization rate (number of 2-cell embryos/ number of oocytes surviving ICSIX100) over all experiments was $91.5 \%$.

Table 1 Number of surviving oocytes injected with evaporatively dried sperm stored for various times at different temperatures that developed to the 2-cell stage (the percentages are assumed to be estimates of the fertilization rates).

\begin{tabular}{lllll}
\hline & \multicolumn{4}{c}{ Storage time } \\
\cline { 2 - 5 } $\begin{array}{l}\text { Storage } \\
\text { temperature }\end{array}$ & 1 week & 1 month & 3 months & 5 months \\
\hline $4{ }^{\circ} \mathrm{C}$ & $36 / 39$ & $40 / 46$ & $37 / 42$ & $49 / 53$ \\
& $(92.3 \%)$ & $(87.0 \%)$ & $(88.1 \%)$ & $(92.5 \%)$ \\
$-20{ }^{\circ} \mathrm{C}$ & $41 / 44$ & $53 / 58$ & $35 / 39$ & $47 / 50$ \\
& $(93.2 \%)$ & $(91.4 \%)$ & $(89.7 \%)$ & $(94.0 \%)$ \\
$-80{ }^{\circ} \mathrm{C}$ & $48 / 52$ & $43 / 45$ & $39 / 44$ & $46 / 50$ \\
& $(92.3 \%)$ & $(95.6 \%)$ & $(88.6 \%)$ & $(92.0 \%)$ \\
$P^{\text {a }}$ & 1 & 0.182 & 1 & 1 \\
\hline
\end{tabular}

$P^{\mathrm{a}}$, probability that the distributions of 1 - and 2-cell stages for each storage time are not significant different (exact Jonckhere-Terpstra test).

\section{Effects of time and temperature of sperm storage on embryo development}

The effects of the storage time and temperature of the evaporatively dried spermatozoa on the development of ICSI-fertilized oocytes are summarized in Table 2. There were no significant differences between the distribution of embryos at various stages of development reached after 96-98 h culture of embryos derived using evaporatively dried spermatozoa stored for 1 week at $4,-20$, and $-80{ }^{\circ} \mathrm{C}$ (Table 2a). The total blastocyst formation rates at $4,-20$, and $-80^{\circ} \mathrm{C}$ were $77.8,78.0$, and $81.3 \%$ respectively. Similarly, there were no significant differences between the distributions of embryos at various stages of development reached after 96-98 h culture of embryos derived using evaporatively dried spermatozoa stored for 1 month at $4,-20$, and $-80^{\circ} \mathrm{C}$ (Table 2b), and the total blastocyst formation rates at $4,-20$, and $-80^{\circ} \mathrm{C}$ were $72.5,81.1$, and $79.5 \%$ respectively. In contrast, there was a significant difference in the distributions of embryos derived from evaporatively dried spermatozoa stored at $4,-20$, and $-80^{\circ} \mathrm{C}$ for 3 months (Table 2c), and the total blastocyst formation rates at $4,-20$, and $-80{ }^{\circ} \mathrm{C}$ were $35.1,54.3$, and $74.4 \%$ respectively. Fewer blastocysts developed from oocytes fertilized with spermatozoa stored at 4 and $-20^{\circ} \mathrm{C}$, while more embryos stopped development at the 5-8-cell stage. The results using spermatozoa stored for 5 months were very similar to those obtained with spermatozoa stored for 3 months (Table $2 \mathrm{~d}$ ). Blastocyst formation rates using spermatozoa stored for 5 months at $-20^{\circ} \mathrm{C}(57.4 \%)$ or $-80{ }^{\circ} \mathrm{C}(74.5 \%)$ were not significantly different from those stored for 3 months at the same temperatures respectively, but were significantly better than that stored for 5 months at $4{ }^{\circ} \mathrm{C}(10.2 \%)$.

A linear logistic regression analysis has been done on the data for each storage temperature. The estimated parameters of each regression line $(a, b)$ are shown in Table 3, where the $b^{\prime}$ s, the regression coefficients, can be regarded as the measures of the rate constants describing the deterioration of the spermatozoa over time. Goodness-of-fit tests showed that simple linear regressions fitted the data in all three sets of data. There is a highly significant negative regression of the response on storage time for the data obtained when the spermatozoa were stored at $4{ }^{\circ} \mathrm{C}(b=-0.185,95 \%$ confidence limits: -0.242 to -0.129$)$, demonstrating a marked deterioration of the spermatozoa over time. There is also a significant, but steeper, negative regression when the spermatozoa were stored at $-20{ }^{\circ} \mathrm{C}(b=-0.064,95 \%$ confidence limits: -0.107 to -0.021$)$, demonstrating that the deterioration of the spermatozoa was partially slowed at $-20^{\circ} \mathrm{C}$ when compared with $4{ }^{\circ} \mathrm{C}$. In contrast, the negative regression when the spermatozoa were stored at $-80^{\circ} \mathrm{C}$ was not statistically significant $(b=-0.021,95 \%$ confidence 
Table 2 The development of embryos at various stages of development (2-cell through hatching blastocysts, 96-98 h after intracytoplasmic sperm injection (ICSI) from ICSI-fertilized oocytes using evaporatively dried spermatozoa after (a) 1 week storage (total blastocyst formation rates at $4,-20$, and $-80^{\circ} \mathrm{C}$ were $77.8,78.0$, and $81.3 \%$ respectively), (b) 1 month storage (total blastocyst formation rates at $4,-20$, and $-80{ }^{\circ} \mathrm{C}$ were $72.5,81.1$, and $79.5 \%$ respectively), (c) 3 months storage (total blastocyst formation rates at $4,-20$, and $-80{ }^{\circ} \mathrm{C}$ were $35.1,54.3$, and $74.4 \%$ respectively), and (d) 5 months storage (total blastocyst formation rates at $4,-20$, and $-80{ }^{\circ} \mathrm{C}$ were $10.2,57.4$, and $74.5 \%$ respectively).

\begin{tabular}{|c|c|c|c|c|c|c|c|}
\hline \multirow[b]{2}{*}{$\begin{array}{l}\text { Storage } \\
\text { temperature }\left({ }^{\circ} \mathrm{C}\right)\end{array}$} & \multicolumn{7}{|c|}{ No. of embryos (\%) } \\
\hline & 2-cell & 3,4-cell & 5-8-cell & $\begin{array}{l}\text { Compacted } \\
\text { morulae }\end{array}$ & $\begin{array}{l}\text { ZP-enclosed } \\
\text { blastocysts }\end{array}$ & $\begin{array}{l}\text { Hatching } \\
\text { blastocysts }\end{array}$ & $\begin{array}{l}\text { Total } \\
\text { embryos }\end{array}$ \\
\hline \multicolumn{8}{|l|}{ (a) 1 Week storage } \\
\hline $4{ }^{\circ} \mathrm{C}$ & $1(2.8)$ & $2(5.6)$ & $2(5.6)$ & $3(8.3)$ & $9(25.0)$ & $19(52.8)$ & $36(100)$ \\
\hline$-20^{\circ} \mathrm{C}$ & $1(2.4)$ & $2(4.9)$ & $3(7.3)$ & $3(7.3)$ & $11(26.8)$ & $21(51.2)$ & $41(100)$ \\
\hline$-80^{\circ} \mathrm{C}$ & $3(6.3)$ & $2(4.2)$ & $3(6.3)$ & $1(2.1)$ & $12(25.0)$ & $27(56.3)$ & $48(100)$ \\
\hline \multicolumn{8}{|c|}{ (b) 1 Month storage } \\
\hline $4{ }^{\circ} \mathrm{C}$ & $4(10.0)$ & $4(10.0)$ & $3(7.5)$ & $0(0.0)$ & $10(25.0)$ & $19(47.5)$ & $40(100)$ \\
\hline$-20^{\circ} \mathrm{C}$ & $1(1.9)$ & $2(3.8)$ & $3(5.7)$ & $4(7.6)$ & $11(20.8)$ & $32(60.4)$ & $53(100)$ \\
\hline$-80^{\circ} \mathrm{C}$ & $4(9.1)$ & $1(2.3)$ & $2(4.6)$ & $2(4.6)$ & $8(18.2)$ & $27(61.4)$ & $44(100)$ \\
\hline \multicolumn{8}{|c|}{ (c) 3 Months storage } \\
\hline $4{ }^{\circ} \mathrm{C}$ & $4(10.8)$ & $2(5.4)$ & $15(40.5)$ & $3(8.1)$ & $5(13.5)$ & 8 (21.6) & $37(100)$ \\
\hline$-20^{\circ} \mathrm{C}$ & $2(5.7)$ & $1(2.9)$ & $11(31.4)$ & $2(5.7)$ & $6(17.1)$ & $13(37.1)$ & $35(100)$ \\
\hline$-80^{\circ} \mathrm{C}$ & $3(7.7)$ & $3(7.7)$ & $4(10.3)$ & $0(0.0)$ & $10(25.6)$ & $19(48.7)$ & $39(100)$ \\
\hline \multicolumn{8}{|c|}{ (d) 5 Months storage } \\
\hline $4{ }^{\circ} \mathrm{C}$ & $0(0.0)$ & $11(22.5)$ & $18(36.7)$ & $15(30.6)$ & $5(10.2)$ & $0(0.0)$ & $49(100)$ \\
\hline$-20^{\circ} \mathrm{C}$ & $1(2.1)$ & $5(10.6)$ & $9(19.2)$ & $5(10.6)$ & $8(17.0)$ & $19(40.4)$ & $47(100)$ \\
\hline$-80^{\circ} \mathrm{C}$ & $2(4.3)$ & $2(4.3)$ & $5(10.6)$ & $3(6.4)$ & $5(10.6)$ & $30(63.8)$ & $47(100)$ \\
\hline
\end{tabular}

Differences in the distribution of embryos at various developmental stages for each storage time are not statistically significant $(($ a) $P=0.775$; (b) $P=0.23$; (c) $P=0.00644$; (d) $P<0.0001$, exact Jonckhere-Terpstra test); $Z \mathrm{P}$, zona pellucida.

limits: -0.068 to 0.025$)$, demonstrating that at $-80^{\circ} \mathrm{C}$ the degeneration of the spermatozoa was prevented. Table 3 also includes estimates obtained when the dried spermatozoa were stored at $22{ }^{\circ} \mathrm{C}$, published in a previous paper (McGinnis et al. 2005). The significant negative regression coefficient $(b=-1.053)$ was steeper than that obtained from the $4{ }^{\circ} \mathrm{C}$ data, showing that the spermatozoa deteriorated even more quickly at $22^{\circ} \mathrm{C}$ than those stored at $4{ }^{\circ} \mathrm{C}$.

The regression lines obtained for the four temperatures are shown in Fig. 1 after the responses have been transformed back to the percentage scale using the equation:

$p=\frac{\mathrm{e}^{y}}{1+\mathrm{e}^{y}}$.

Figure 1 relates the total percentage of blastocysts (zona-enclosed +hatching) to the storage time for each of the three storage temperatures. The curves demonstrate clearly the large effect, the storage temperature has on the preservation of the spermatozoa injected into the ova. The data obtained by McGinnis et al. (2005) at $22{ }^{\circ} \mathrm{C}$ are also included in Fig. 1 showing the very rapid deterioration of the dried spermatozoa when stored at ambient temperature.

Cryobiologists are frequently interested in predicting the survivability of preserved material after very prolonged storage. This procedure was done recently by Kawase et al. (2005) in their studies on freeze-dried mouse spermatozoa employing the widely used Arrhenius plot. Since our data are categorical, an alternative, more direct estimate of survival times can be obtained from Eq. (1) computed by logistical regression analysis. Solving Eq. (1) for $t$ gives:

$t=\frac{y-a}{b}$

The time for any percentage loss can then be calculated by substituting $y$ with the logit of the percentage loss of interest. Thus, for a $90 \%$ loss, $y=$ $\ln (0.1 / 0.9)=0.105$. For $50 \%$ loss (half-life), $y=\ln (0.5 /$ $0.5)=0$. The results from these calculations applied to the four regressions are summarized in Table 4. The results suggest that dried spermatozoa can survive very long periods when stored at $-80^{\circ} \mathrm{C}$ after the process of drying is finished. It should be emphasized, however, that the values of the parameters in Table 3, particularly those calculated from -80 to $-20^{\circ} \mathrm{C}$, could be biased due to lack of the fit of the statistical model used and also the fact that the estimates are subject to large errors because of the extrapolation involved.

An Arrhenius plot of our data is shown in Fig. 2 using the estimates of $b$ in Table 3. The points do not appear to fall on a linear line. The Arrhenius plot is discontinuous, possibly because the decay rates are different below and above $T_{\mathrm{g}}$ (the glass transition temperature), the rate of deterioration being much less below $T_{\mathrm{g}}$ than above $T_{\mathrm{g}}$. Such discontinuities in Arrhenius plots are well known in both biochemical and biological systems (e.g. Leopold 1980, Biosca et al. 1983). Studies on the survival of spermatozoa at several more storage temperatures above and below $T_{\mathrm{g}}$ are needed to detect this hypothetical discontinuity. 
Table 3 The estimated parameters and their confidence limits $(P=0.95)$ of the logistic regressions $\left(b\right.$ and $\alpha_{1}$ ) fitted to the data obtained from storage at $-80,-20,4$, and $22{ }^{\circ} \mathrm{C}$.

\begin{tabular}{lll}
\hline $\begin{array}{l}\text { Storage } \\
\text { temperature } \\
\left({ }^{\circ} \mathrm{C}\right)\end{array}$ & \multicolumn{1}{c}{$\boldsymbol{b}$} & \multicolumn{1}{c}{$\boldsymbol{a}$} \\
\hline-80 & $-0.021(-0.067$ to 0.025$)$ & $1.44(0.87$ to 2.01$)$ \\
-20 & $-0.064(-0.107$ to -0.021$)$ & $1.414(0.861$ to 1.968$)$ \\
4 & $-0.185(-0.242$ to -0.129$)$ & $1.591(0.978$ to 2.203$)$ \\
22 & $-1.053(-1.536$ to -0.571$)$ & $1.011(0.130$ to 1.893$)$ \\
\hline
\end{tabular}

\section{Effects of time and temperature of sperm storage on development of live-born offspring}

The results of surgically transferring 2-cell stage embryos derived using evaporatively dried spermatozoa, stored for 1 month at $4,-20$, and $-80^{\circ} \mathrm{C}$ into surrogate mothers are summarized in Table 5 . The results suggest that there is a downward trend in the percentage of newborn mice as the storage temperature rises from -80 to $4{ }^{\circ} \mathrm{C}$. The trend, however, is not statistically significant at the $P=0.05$ level of significance. When this putative trend is ignored, the overall percentage of young born is $33.9 \%$ (56/165). All of the mice that were born were successfully weaned and some were mated to yield a new generation of 87 mice that appeared grossly normal. No significant differences in the sex ratios were observed between any of the groups throughout the experiment.

The results of surgically transferring blastocyst embryos derived by ICSI using evaporatively dried

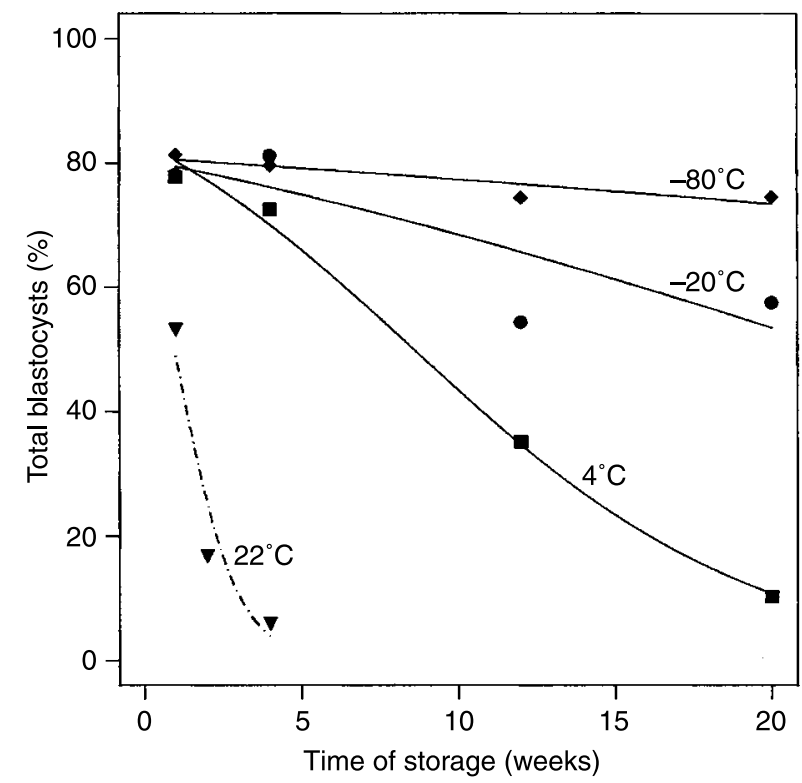

Figure 1 The percentage of blastocysts (zona-enclosed + hatching) that developed using sperm that had been stored for 1 week and 1,3 , and 5 months at $4,-20$, and $-80{ }^{\circ} \mathrm{C}$., $4{ }^{\circ} \mathrm{C} ; \bullet,-20{ }^{\circ} \mathrm{C} ; \bullet,-80{ }^{\circ} \mathrm{C}$. The scale of the abscissa is in weeks where 1 month is assumed to be 4 weeks. Data from McGinnis et al. (2005) where spermatozoa were stored at $22{ }^{\circ} \mathrm{C}$ are also included in the diagram $(\boldsymbol{\nabla})$.
Table 4 The estimated time (weeks) for a loss of 50 and 90\% dried spermatozoa at different storage temperatures.

\begin{tabular}{lcc}
\hline $\begin{array}{l}\text { Storage temperature } \\
\left({ }^{\circ} \mathrm{C}\right)\end{array}$ & $\begin{array}{c}\mathbf{5 0 \%} \text { loss } \\
\text { (half-life in weeks) }\end{array}$ & $\begin{array}{c}\mathbf{9 0 \%} \text { loss } \\
\text { (weeks) }\end{array}$ \\
\hline-80 & 69 & 173 \\
-20 & 22 & 56 \\
4 & 9 & 20 \\
22 & 1 & 3 \\
\hline
\end{tabular}

spermatozoa, stored for 3 and 5 months at $4,-20$, and $-80{ }^{\circ} \mathrm{C}$ into surrogate mothers are summarized in Table 6 . The percentages of newborn obtained using spermatozoa stored for 3 and 5 months at -20 and $-80{ }^{\circ} \mathrm{C}$ are very similar (overall mean $60 / 110 ; 54.5 \%$ ). The use of spermatozoa stored for 3 months at $4{ }^{\circ} \mathrm{C}$ resulted in the birth of 5 young $(38.5 \%)$, but this is not significantly lower than the $\sim 56 \%$ born using spermatozoa stored at -20 and $-80{ }^{\circ} \mathrm{C}$. No young were born using spermatozoa stored for 5 months at $4{ }^{\circ} \mathrm{C}$ but this result was also not significant. However, these two nonsignificant results may be due to the low numbers of blastocysts transferred, since it is well known that embryos transferred alone have little chance of survival.

All of the mice that were born were successfully weaned (Fig. 3). Some of the mice born after using spermatozoa stored for 5 months were mated to yield a new generation of 56 mice that appeared grossly normal. No significant differences in the sex ratios were observed between any of the groups throughout the experiment.

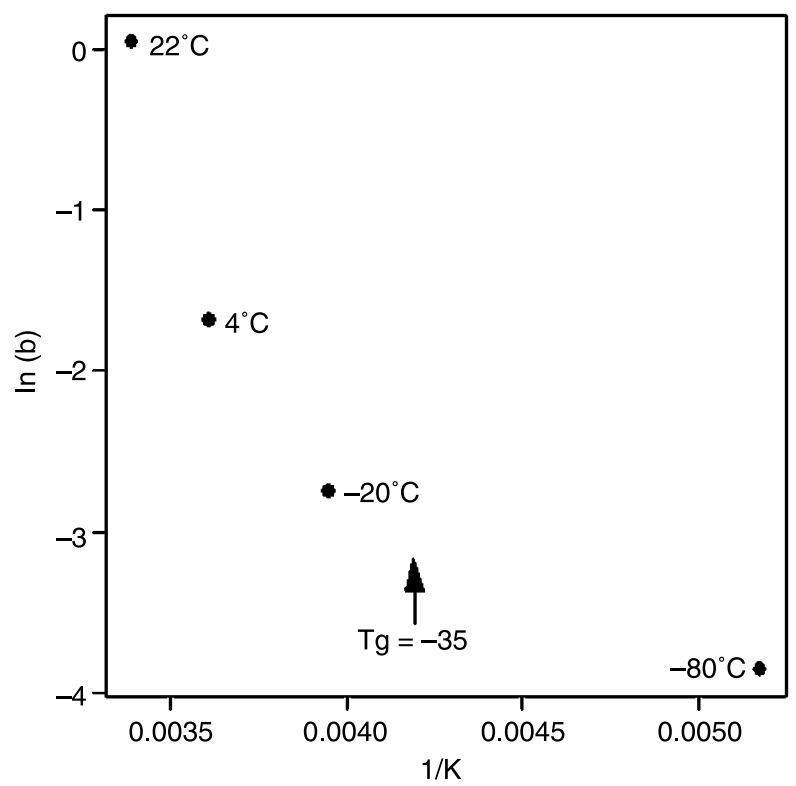

Figure 2 An Arrhenius plot of the natural logarithm of the rate constants ( $b$ in Table 3 ) versus the reciprocal of the absolute temperature $(T)$, and the glass transition temperature $\left(T_{\mathrm{g}}\right)$. 
Table 5 (a) The number and gender of offspring born and weaned after transfer of Intracytoplasmic sperm injection (ICSI)-derived 2-cell embryos produced from evaporatively dried sperm stored for 1 month at $4,-20$, and $-80^{\circ} \mathrm{C}$ respectively; (b) the number and gender of offspring born after natural mating of sexually mature mice derived from a subset of embryos in ' $a$ '.

\begin{tabular}{|c|c|c|c|c|c|}
\hline Storage temperature & No. of recipients & $\begin{array}{l}\text { No. of 2-cell } \\
\text { embryos } \\
\text { transferred }\end{array}$ & $\begin{array}{l}\text { No. of pups born } \\
\text { (transfer rate, \%) }\end{array}$ & $\begin{array}{l}\text { No. of pups weaned } \\
\text { (weaning rate, \%) }\end{array}$ & $\begin{array}{c}\text { Sex ratio } \\
(M / F)\end{array}$ \\
\hline \multicolumn{6}{|c|}{ (a) Liveborn offspring from ICSI-derived embryos after 1 month sperm storage } \\
\hline $4{ }^{\circ} \mathrm{C}$ & 3 & 63 & $17(27.0)$ & $17(100)$ & $6 / 11$ \\
\hline$-20^{\circ} \mathrm{C}$ & 3 & 56 & $20(35.7)$ & $20(100)$ & $12 / 8$ \\
\hline$-80^{\circ} \mathrm{C}$ & 3 & 46 & $19(41.3)$ & $19(100)$ & $7 / 12$ \\
\hline Storage temperature & & No. of matings & No. of pup & Sex & $(\mathrm{M} / \mathrm{F})$ \\
\hline \multicolumn{6}{|c|}{ (b) Liveborn offspring after natural mating of mice born from ICSI-derived embryos in ' $a$ '. } \\
\hline \multicolumn{2}{|c|}{$4{ }^{\circ} \mathrm{C}$} & 3 & 28 & \multicolumn{2}{|c|}{$12 / 16$} \\
\hline \multicolumn{2}{|l|}{$-20^{\circ} \mathrm{C}$} & 3 & 26 & \multicolumn{2}{|c|}{$12 / 14$} \\
\hline \multicolumn{2}{|l|}{$-80^{\circ} \mathrm{C}$} & 4 & 33 & \multicolumn{2}{|c|}{$18 / 15$} \\
\hline
\end{tabular}

(a) Probability that the percentage born at each storage temperature are not significantly different $(P=0.113$, exact Kruskal-Wallis test).

\section{Discussion}

Trehalose is a nonreducing disaccharide formed from two glucose units joined by a $1-1 \alpha$ bond. It is found in the cells of many organisms that naturally survive dehydration, a phenomenon known as 'anhydrobiosis' (Crowe \& Crowe 2000, Elbein et al. 2003). It protects the organisms against various stresses, such as dryness, freezing, and osmotic pressure. Previous studies have demonstrated that trehalose can also protect mammalian cells, and the presence of trehalose on both sides of the cell membrane can maximize the protective effect of trehalose during cell freezing and drying (Chen et al. 2001, Buchanan et al. 2005).

Trehalose was also found to have protective effect on evaporatively dried mouse spermatozoa (McGinnis et al. 2005), in which the mouse sperm samples were evaporatively dried by nitrogen gas for $5 \mathrm{~min}$ at $10 \mathrm{l} / \mathrm{min}$ flow rate. Longer drying time, which reduced the water content in the sperm samples, significantly reduced the sperm capability to support embryo development to the blastocyst stage (McGinnis et al. 2005). This work described in the present report utilized the evaporative drying of mouse spermatozoa following the method published previously (McGinnis et al. 2005), and mainly focused on the technical aspect rather than the mechanism of how the trehalose protects the cells and the precise nature of sperm deterioration.

The results in Table 1 that there were no significant differences between the fertilization rates, or numbers of fertilized oocytes injected with evaporatively dried spermatozoa that developed to the 2-cell stage, after storage at any of the tested temperatures $(4,-20$, and $-80^{\circ} \mathrm{C}$ ) and storage times ( 1 week and 1, 3, and 5 months) indicated that mouse sperm factors required for egg activation and fertilization are very stable, which confirms the previously published data (McGinnis et al. 2005). The capability of the oocytes that were fertilized with evaporatively dried spermatozoa stored at $4{ }^{\circ} \mathrm{C}$ to develop into blastocysts in vitro is progressively impaired as storage time is increased (Table 2, Fig. 1). This deterioration can be considerably reduced when the

Table 6 The number and gender of offspring born and weaned after transfer of Intracytoplasmic sperm injection (ICSI)-derived blastocysts produced from evaporatively dried sperm stored for (a) 3 months and (b) 5 months at $4,-20$, and $-80^{\circ} \mathrm{C}$ respectively; (c) the number and gender of offspring born after natural mating of sexually mature mice derived from a subset of embryos in ' $b$ '.

\begin{tabular}{|c|c|c|c|c|c|}
\hline $\begin{array}{l}\text { Storage } \\
\text { temperature }\end{array}$ & No. of recipients & $\begin{array}{l}\text { No. of blastocysts } \\
\text { transferred }\end{array}$ & $\begin{array}{l}\text { No. of pups born } \\
\text { (transfer rate, \%) }\end{array}$ & $\begin{array}{l}\text { No. of pups weaned } \\
\text { (weaning rate, \%) }\end{array}$ & $\begin{array}{c}\text { Sex ratio } \\
(M / F)\end{array}$ \\
\hline \multicolumn{6}{|c|}{ (a) Liveborn offspring from ICSI-derived embryos after 3 months sperm storage } \\
\hline $4{ }^{\circ} \mathrm{C}$ & 3 & 13 & $5(38.5)$ & $5(100)$ & $2 / 3$ \\
\hline$-20^{\circ} \mathrm{C}$ & 3 & 19 & $11(57.9)$ & $11(100)$ & $4 / 7$ \\
\hline$-80^{\circ} \mathrm{C}$ & 3 & 29 & $16(55.2)$ & $16(100)$ & $10 / 6$ \\
\hline \multicolumn{6}{|c|}{ (b) Liveborn offspring from ICSI-derived embryos after 5 months sperm storage } \\
\hline $4{ }^{\circ} \mathrm{C}$ & 3 & 5 & $0(0.0)$ & - & - \\
\hline$-20^{\circ} \mathrm{C}$ & 3 & 27 & $14(51.9)$ & $14(100)$ & $8 / 6$ \\
\hline$-80^{\circ} \mathrm{C}$ & 3 & 35 & $19(54.3)$ & $19(100)$ & $11 / 8$ \\
\hline \multicolumn{2}{|c|}{ Storage temperature } & No. of matings & No. of pups & \multicolumn{2}{|c|}{ Sex ratio $(M / F)$} \\
\hline \multicolumn{6}{|c|}{ (c) Liveborn offspring after natural mating of mice born from ICSI-derived embryos in 'b' } \\
\hline \multirow{2}{*}{\multicolumn{2}{|c|}{$\begin{array}{l}-20^{\circ} \mathrm{C} \\
-80^{\circ} \mathrm{C}\end{array}$}} & 3 & 29 & \multicolumn{2}{|c|}{$17 / 12$} \\
\hline & $-80^{\circ} \mathrm{C}$ & 3 & 27 & \multicolumn{2}{|c|}{$13 / 14$} \\
\hline
\end{tabular}

Probability that the percentage born at each storage temperature are not significantly different ((a) $P=0.458$; (b) $P=0.168$, exact Kruskal-Wallis test). 


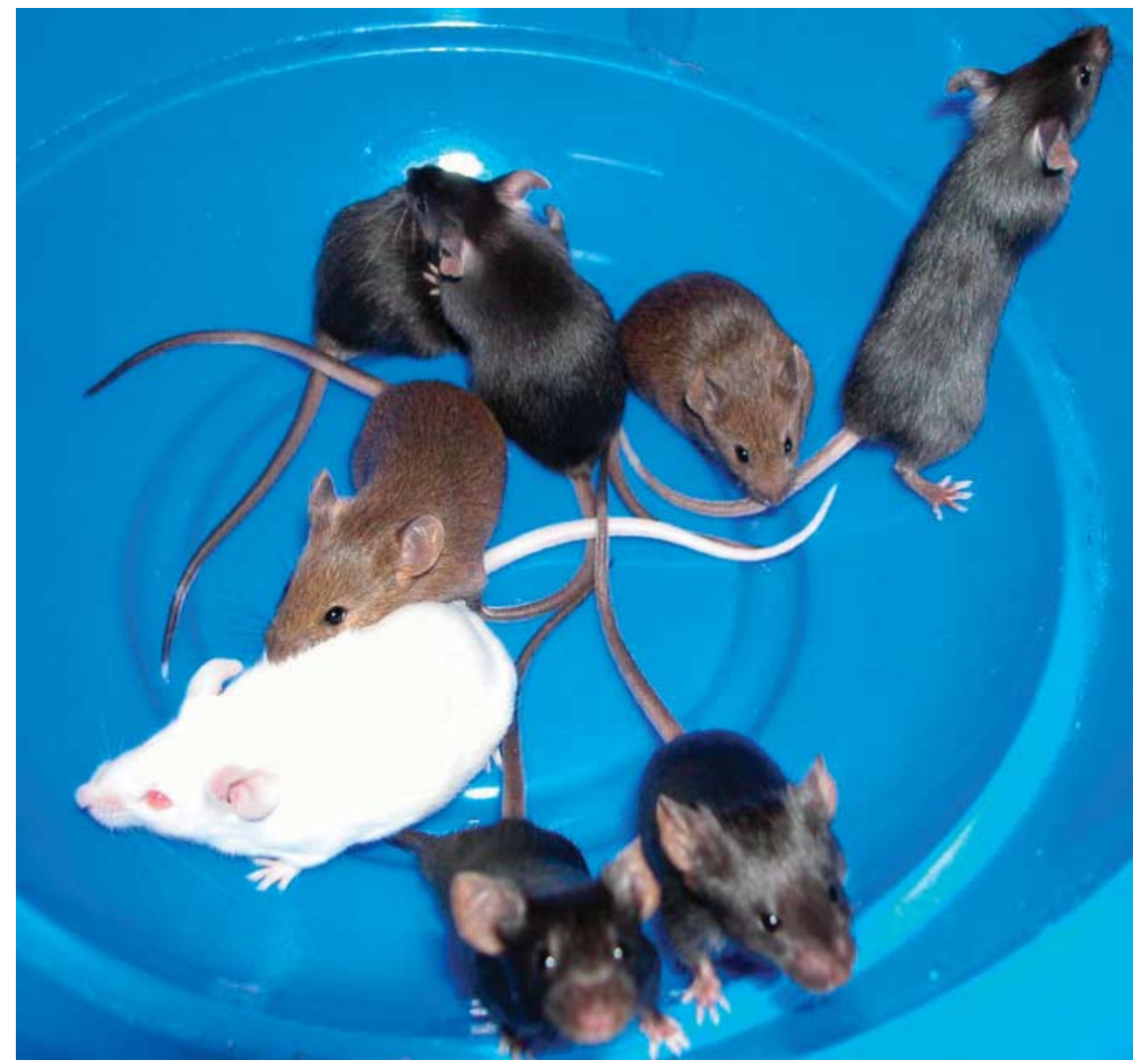

Figure 3 Litter derived by ICSI using evaporatively dried sperm that had been stored for 3 months at $-80^{\circ} \mathrm{C}$. White mouse is CD-1 surrogate mother. evaporatively dried spermatozoa are stored at lower temperature $\left(-20\right.$ or $\left.-80{ }^{\circ} \mathrm{C}\right)$, especially when the evaporatively dried spermatozoa are stored for 5 months at $-80^{\circ} \mathrm{C}$.

Our results demonstrate for the first time that partially evaporatively dried mouse spermatozoa in trehaloseEGTA solution can be preserved for 5 months at $-80{ }^{\circ} \mathrm{C}$. This result is comparable with those obtained by Kawase et al. (2005) who successfully stored freeze-dried spermatozoa at $-80{ }^{\circ} \mathrm{C}$ for 6 months. Our estimates of viability obtained by extrapolation of fitted logistic equations suggest that the half-life of the spermatozoa stored at $-80^{\circ} \mathrm{C}$ may be about 67 weeks. Kawase et al. (2005) used accelerated stability analysis based on Arrhenius plots, from which they report very long survival times. However, their analyses need critical examination, since the Arrhenius plot they used was based on spermatozoa stored for no more than 7 days at relatively high temperatures $\left(30,40\right.$, and $\left.50{ }^{\circ} \mathrm{C}\right)$. The Arrhenius plot of this data was then extrapolated to predict the rate of blastocyst development at 25, 4, -20, and $-80{ }^{\circ} \mathrm{C}$. This extreme extrapolation does not take into account the possibility that the Arrhenius plot is discontinuous at the glass transition temperature. Mouse spermatozoa are usually stored using cryopreservation in liquid nitrogen. Recently, Kaneko et al. (2006) reported that cryopreserved mouse spermatozoa have been successfully stored in liquid nitrogen for at least 10 years. Our analysis supports the hypothesis that evaporatively dried sperm will survive at least 3 years storage at $-80{ }^{\circ} \mathrm{C}$, and likely even longer in liquid nitrogen.

It is possible that the sperm damage caused during storage interferes with the properties of the embryo genes contributed by the spermatozoa, since these do not become functional until late in the 2-cell stage of development after the zygotic transition (Schultz 2002). The precise nature of sperm deterioration associated with storage time and temperature is probably DNA damage. Mouse spermatozoa with damaged DNA induced by gamma radiation could fertilize the oocytes in vitro normally, but the blastocyst formation rate was significantly decreased (Ahmadi \& Ng 1999). Bovine spermatozoa with damaged DNA induced by X-ray radiation were also normally capable of fertilizing oocytes in vitro, but further embryonic development was almost completely blocked before blastocyst formation, and this block in embryonic development was accompanied with the initiation of apoptosis after the second or third cleavage (Fatehi et al. 2006). DNA damage assay demonstrated directly that sperm DNA damage occurred when freeze-dried mouse spermatozoa were stored at $4{ }^{\circ} \mathrm{C}$ rather than at $-80{ }^{\circ} \mathrm{C}$ (Kawase et al. 2005).

Our data clearly show that mouse spermatozoa in the same population vary widely in their susceptibility to damage. Some are robust and are able to stimulate 
development of the injected oocytes to the blastocyst stage even after 3 months storage at $4{ }^{\circ} \mathrm{C}$. These blastocysts are then capable of developing into normal mice after they are transferred into recipient females. Our results also demonstrate convincingly that, irrespective of storage time and temperature of evaporatively dried spermatozoa, once an ICSI-derived embryo develops to a 'normal' blastocyst, that embryo is highly likely to develop to term and become a liveborn mouse that survives to weaning and sexual maturity and is reproductively sound. Thus, the formation of a blastocyst is a reliable and useful indicator that an oocyte has been fertilized by an evaporatively dried spermatozoon that has not been damaged by the particular drying, storage, and rehydration protocols used.

We believe that the long-term preservation of mouse spermatozoa by evaporative drying coupled with storage at $-80^{\circ} \mathrm{C}$ is a viable technique that can be carried out under normal laboratory conditions and applied to a number of practical situations. The method avoids the use of complex equipment for freezing and freezedrying and the use of liquid nitrogen. Further, the technique facilitates sharing and distribution of spermatozoa among researchers worldwide by enabling shortterm transport at temperatures as high as $4{ }^{\circ} \mathrm{C}$.

\section{Acknowledgements}

The project described was supported by Grant Numbers R24 RR018934 and U42 RR14905 from the National Center for Research Resources (NCRR), a component of the National Institutes of Health $(\mathrm{NIH})$. Its contents are solely the responsibility of the authors and do not necessarily represent the official views of NCRR or NIH. This project was also supported by the UC Davis Mouse Biology Program. Supported by NIH/NCRR grant no. R24RR018934, NIH/NCRR grant no. U42 RR14905 to the Mutant Mouse Regional Research Center (MMRRC), and UC Davis Mouse Biology Program The authors declare that there is no conflict of interest that would prejudice the impartiality of this scientific work.

\section{References}

Ahmadi A \& Ng SC 1999 Fertilizing ability of DNA-damaged spermatozoa. Journal of Experimental Zoology 284 696-704.

Bhowmick S, Zhu L, McGinnis L, Lawitts J, Nath BD, Mehmet T \& Biggers JD 2003 Desiccation tolerance of spermatozoa dried at ambient temperature: production of fetal mice. Biology of Reproduction 68 1779-1786.

Biggers JD, McGinnis LK \& Raffin M 2000 Amino acids and preimplantation development of the mouse in ptrotein-free potassium simplex optimized medium. Biology of Reproduction 63 281-293.

Biosca JA, Travers F \& Barman TE 1983 A jump in an Arrhenius plot can be the consequence of a phase transition. FEBS Letters 153 217-220.

Buchanan SS, Menze MA, Hand SC, Pyatt DW \& Carpenter JF 2005 Cryopreservation of human hematopoietic stem and progenitor cells loaded with thehalose: transient permeabilization via the adenosine triphosphate-dependent P2Z receptor channel. Cell Preservation Technology 3 212-222.
Chen T, Fowler A \& Toner M 2000 Literature review: supplemented phase diagram of the trehalose-water binary mixture. Criobiology 40 277-282.

Chen T, Acker JP, Eroglu A, Cheley S, Bayley H, Fowler A \& Toner M 2001 Beneficial effect of intracellular trehalose on the membrane integrity of dried mammalian cells. Cryiobiology 43 168-181.

Crowe JH \& Crowe LM 2000 Preservation of mammalian cells learning nature's tricks. Nature Biotechnology 18 145-146.

Crowe JH, Crowe LM, Oliver AE, Tsvetkova N, Wolkers W \& Tablin F 2001 The trehalose myth revisited: introduction to a symposium on stabilization of cells in the dry state. Cryobiology 43 89-105.

Elbein AD, Pan YT, Pastuszak I \& Carroll D 2003 New insights on trehalose: multifunctional molecule. Glycobiology 13 17R-27R.

Eroglu A, Russo MJ, Bieganski R, Fowler A, Cheley S, Bayley H \& Toner M 2000 Intracellular trehalose improves the survival of cryopreserved mammalian cells. Nature Biotechnology $\mathbf{1 8}$ 163-167.

Fatehi AN, Bevers MM, Schoevers E, Roelen BA, Colenbrander B \& Gadella BM 2006 DNA damge in bovine sperm does not block fertilization and early embryonic development but induces apoptosis after the first cleavages. Journal of Andrology 27 176-188.

Green JL \& Angell CA 1998 Phase relations and vitrification of saccharide-water solutions and the trehalose anomaly. Journal of Physical Chemistry 93 2880-2882.

Homer DW \& Lemeshow S 1989 Applied Logistic Regression, New York: Wiley.

Kaneko T \& Nakagata N 2005 Relation between storage temperature and fertilizing ability of freeze-dried mouse spermatozoa. Comparative Medicine 55 140-144.

Kaneko T, Yamamura A, Ide Y, Qgi M, Yanagita T \& Nakagata N 2006 Long-term cryopreservation of mouse sperm. Theriogenology 266 1098-1101.

Katkov II \& Levine F 2004 Prediction of the glass transition temperature of water solutions: comparison of different models. Cryobiology 49 $62-82$.

Kawase Y, Araya H, Kamada N, Jishage K \& Suzuki H 2005 Possibility of long-term preservation of freeze-dried mouse spermatozoa. Biology of Reproduction 72 568-573.

Kimura Y \& Yanagimachi R 1995 Intracytoplasmic sperm injection in the mouse. Biology of Reproduction 52 709-720.

Knight J \& Abbott A 2002 Mouse genetics: full house. Nature 417 785-786.

Kusakable H, Szczygiel MA, Whittingham DG \& Yanagimachi R 2001 Maintenance of genetic integrity in frozen and freeze-dried mouse spermatozoa. PNAS 98 13501-13506.

Landel CP 2005 Archiving mouse strains by cryopreservation. Lab Animal 34 50-57.

Lawitts JA \& Biggers JD 1993 Culture of preimplantation embryos. Methods in Enzymology 225 153-164.

Lee KB \& Niwa K 2006 Fertilization and development in vitro of bovine oocytes following intracytoplasmic injection of heat-dried sperm heads. Biology of Reproduction 74 146-152.

Leopold AC 1980 Temperature effects on soybean imbibition and leakage. Plant Physiology 65 1096-1098.

Li MW \& Lloyd KCK 2006 Intracytoplasmic sperm injection (ICSI) in the mouse. In Principles and Practice: Mammalian and Avian Transgenesis - New Approaches, pp 23-40. Eds S Pease \& C Lois. Berlin Heidelberg: Springer-Verlag.

Li MW, McGinnis L, Zhu L, Lawitts J, Biggers JD \& Lloyd KC 2003 Intracytoplasmic sperm injection (ICSI) enables rescue of valuable mutant mouse strains. Comparative Medicine $\mathbf{5 3}$ 265-269.

McCullagh P \& Nelder JA 1989 Generalized Linear Models, 2 London: Chapman and Hall.

McGinnis L, Zhu L, Lawitts J, Bhowmick S, Mehmet T \& Biggers JD 2005 Mouse sperm desiccated and stored in trehalose medium without freezing. Biology of Reproduction 73 627-633. 
Nakagata N 2000 Cryopreservation of mouse spermatozoa. Mammalian Genome 11 572-576.

Roos YH 1997 Frozen state transitions in relation to freeze-drying. Journal of Thermal Analysis and Calorimetry 48 535-544.

Schultz RM 2002 The molecular foundations of the maternal to zygotic transition in the preimplantation embryo. Human Reproduction Update 8 323-331.

Sharp JJ, Linda CC \& Mobraaten LE 2001 Genetically engineered mice: husbandry and resources. Methods in Molecular Biology 158 381-396.

Van Thuan N, Wakayama S, Kishigami S \& Wakayama T 2005 New preservation method for mouse spermatozoa without freezing. Biology of Reproduction 72 444-450.
Wakayama T \& Yanagimachi R 1998 Development of normal mice from oocytes injected with freeze-dried spermatozoa. Nature Biotechnology 16 639-641.

Ward MA, Kaneko T, Kusakabe H, Biggers JD, Whittingham DG \& Yanagimachi R 2003 Long-term preservation of mouse spermatozoa after freeze-drying and freezing without cryoprotection. Biology of Reproduction 69 2100-2108.

Received 7 July 2006

First decision 14 August 2006

Revised manuscript received 11 December 2006

Accepted 29 January 2007 